\title{
Food gardening in Lavender Hill, Cape Town: using adoption rates to estimate the perceived benefit
}

\author{
Simon Hazell (Simon.Lee@alumni.uct.ac.za) \\ Victoria Delbridge (vdelbridge@gmail.com) \\ Beatrice Conradie (Beatrice.Conradie@uct.ac.za) \\ Supervisor: Beatrice Conradie \\ Department: School of Economics \\ Course: Eco3009F
}

\begin{abstract}
This paper assesses the potential benefits derived from homestead-based urban agriculture as well as the constraints faced with implementation. A public benefit organisation, Soil for Life, provided access to the Lavender Hill Community. Fifty participants in the Mothers Unite programme were interviewed. The mean household in the dataset reported a per capita disposable income below the official poverty line and none of the households in the sample were able to buy the recommended five a day fruit and vegetables in the formal market. If these households could become self-sufficient in vegetables they would free up an average of $11 \%$ of household income for other expenditures. Despite the great potential of food gardening to relieve food insecurity, and despite respondents identifying with the opportunity to also produce small amounts of vegetables for sale, two thirds of the group have not tried it. The group's lack of gardening experience was patently clear from the factors identified as barriers to adoption. Respondents cited a lack of space and limited cash flow, but people were not really concerned about the cost of water or compost, both crucial factors for success. While it is interesting to know that there is still untapped potential for expanding the program in the area, it is more important to focus future work on why beneficiaries have dropped out of existing programmes.
\end{abstract}

Keywords: food security; urban agriculture; barriers to adoption 


\section{INTRODUCTION}

The policy literature is universal in its support of urban food gardening and generally has very high expectations for it. Cape Town is no exception; local policies are directed to help facilitate the poor's ability to engage in urban agriculture at the a household level in the hope that it will reduce food insecurity levels and provide an alternative livelihood source for the gardeners (City of Cape Town, 2007). Service delivery takes place through a number of public benefit organisations, including but not limited to, Soil for Life, SEED and Abalimi Bezekhaya. Although the details vary, these organisations tend to be part of holistic solutions to community problems which might include early childhood development and afterschool childcare programmes, and might even extend to retrofitting homes to improve energy efficiency, or the use of traditional herbal medicines and business incubation.

Urban agriculture is said to have the potential to address the development goals of poverty alleviation and improved food security (Rogerson, 2003, 2011; Zezza, 2010). This is achieved through providing entrepreneurial opportunities for the unemployed (Rogerson, 2003) as well as improving dietary diversity (Ruysenaar, 2013) and micro nutrient intake (Rogerson, 2011). It is conceded in the literature that the greatest benefit derived from agriculture is accrued to the poorest households and in areas where the formal food markets are inefficient and social grants are at a minimum (Thornton, 2008; Zezza, 2010; Rogerson, 2003 2011; Shisanya and Hendricks, 2011). The literature also documents a number of ways in which gardeners can achieve personal upliftment such as improved health and physical fitness, the development of knowledge and skills, a sense of pride and accomplishment and developing a feeling of independence and self-worth (Shisanya, 2011). Odendaal et al. (2013) argued that by growing one's own food one's relationship with food is changed so that people begin to have more of an appreciation for healthy nutrient-dense foods instead of the cheaper starch-based alternatives.

In addition, urban agriculture is seen to address a number of social goals. Social networks in the community are built through the sharing of crops grown 
(Battersby Leonard, 2011). It is also a means by which mothers are able to contribute positively to their household's livelihood, while simultaneously being able to stay home and take care of their children (Rogerson, 2003). This helps to empower women in the community (Slater, 2001), and perhaps empowers family units to be more resilient to engaging in the social ills that are present in their communities. Ecological objectives are addressed too through urban agriculture in that it 'greens' the city visually, incentivises the recycling of organic waste and grey water as well as increasing biodiversity (Rogerson, 2011). Land that is used for agricultural purposes instead of urbanised construction is also seen to have a higher water absorption capacity and therefore acts as flood control (Lynch et al., 2001). Home-grown organic vegetables are often reported both to taste better (Odendaal et al. 2013) and believed to have a higher nutritional value (Shisanya, 2011).

Service delivery organisations invariably describe urban food gardening programmes as very successful, but then, they have an incentive to do so. There is however substantial evidence emerging that this case may be overstated, and that urban agriculture is in fact quite limited in its ability to ameliorate poverty in urban areas (Lynch et al., 2001; Page, 2002; Thornton, 2008; Webb, 1998a,b, 2011; Webb and Kashumba, 2009; Shisanya and Hendricks, 2011; Ruysenaar, 2013). Webb $(1996,2011)$ found that urban agriculture cannot support development, does not contribute significantly to overall vegetable production, income generation, or selfsufficiency, and does not improve food security or nutrient intake. Gardens that do show positive returns to investment are usually heavily subsidised by government or other private organisations and the benefits are therefore not sustainable (Ruysenaar, 2013). Also, although a home vegetable garden can be maintained at no cost after an initial investment (provided that careful measures are taken such as composting from organic waste and seed catching), many people forget or do not have the time or space to do this. This means that gardens will generally require repeated expenditures and often yield smaller cost savings than other investments (Odendaal et al., 2013). This gives rise to the question of the allocative efficiency of government and private resources in terms of urban agriculture, rather than an alternative measure, to support livelihoods. In addition Lynch et al. (2001) points out that rural production might be preferable to urban agriculture as rural areas have 
relatively lower land prices, cheaper labour supplies, greater water availability and less conflict over property rights.

Several of the studies on the performance of urban agriculture apply costbenefit analysis frameworks and the majority tend to produce negative cost-benefit ratios. The negative outcomes are often due to the inability to properly account for qualitative non-monetisable benefits (Slater, 2001; Austen and Visser, 2002; Zezza, 2010; Rogerson, 2003, 2011; Shisanya and Hendricks, 2011; Odendaal et al., 2013; Ruysenaar, 2013). As an alternative method of analysis, this paper follows the approach in Austen and Visser (2002) by appealing to adoption rates as a measure of the effectiveness of urban agriculture on a household scale. The context is Coloured township in Cape Town characterised by high food insecurity. Despite the many opportunities in place, it the majority of people choose not to maintain any sort of vegetable garden in order to supplement their income or diets. This paper explores why not and what can be done about it.

\section{METHODOLOGY}

Study site

According to the Household Food Insecurity Access Scale, $80 \%$ of households in Cape Town are either moderately or severely food insecure (Battersby Leonard, 2011). Despite containing sufficient calories, diets are often deficient in vitamins and micronutrients as fruit and vegetables are not a priority. Urban agriculture policies aim to give people the opportunity to save money on food as well as encourage people to consume nutrient-dense foods, which ought to translate into numerous health benefits in the community (Geyer et al., 2011).

The study is situated in Lavender Hill, Mitchells Plain, which is officially one of the poorest townships of Cape Town (City of Cape Town, 2012). Among the formal houses are densely populated informal settlements where inhabitants have low standards of living due to high levels of unemployment. Widespread poverty-induced food insecurity, high levels of crime, gang affiliation and drug and alcohol abuse are rife. If urban agriculture has any substantial benefits, it ought to be most easily demonstrated in context such as Lavender Hill (Zezza, 2010). 
Urban agricultural is promoted locally by the public benefit organisation Soil for Life, which is affiliated with Mothers Unite, which provides after-school education facilities and food for the 157 enrolled children every day. Soil for Life provides interested parties in the community with an intensive three-month training course as well as the basic inputs to begin a garden. Inputs include recycled planting containers, potting soil, seedlings and basic gardening equipment. Community members pay a small fee of R15 to partake in this programme, as the organisation believe that they get better commitment when not enrolling community members in a completely free service. Training takes place in groups of a maximum of fifteen people to facilitate a support network between the participants all of whom live within walking distance of one another. The programme also allows for previous programme participants who have successfully established home gardens, to join the training staff and provide assistance to new members, thereby allowing these individuals to earn a stipend. Soil for Life maintains contact with the programme participants for up to four years after training, provided that community members are still actively gardening.

\section{Data collection}

Mothers Unite facilitated access into the community which we visited three times. The first visit entailed piloting our questionnaire with the Mothers Unite staffmembers who live in the community. The main aim of the first visit was to check whether community members would understand the substance of the various questions as well as the language use, as many of them would be interviewed in their second language. Comments were used to refine the questionnaire. The final draft included questions on the importance of vegetables in local diet and perceived constraints to household food gardening. On the second visit, the organisation allowed us to administer the questionnaire to fifty mothers / primary caretakers who showed up for a regular Mothers Unite meeting. One questionnaire was completed per household. Of the fifty questionnaires distributed, six were discarded due to insufficient or incorrect information. A small portion of respondents were unwilling to state their specific income and instead opted to tick one of the income-ranges 
provided. For such observations the bracket midpoint served as a point estimate of household income.

Evaluation of nutrition rates was done by calculating the amount that each household spends on vegetables per person per month. The figures derived from each respective household were then compared to a recommended ' 5 a day' basket. This basket price was calculated by generating ten different bundles, each containing a different mix of five commonly eaten vegetables and fruits whose prices were obtained using 2014 Shoprite prices. The median price of these ten bundles was then taken to serve as an indicator of adequate intake. Shoprite was chosen as the representative food retailer since $68 \%$ of our sample listed this company as their location of choice to acquire vegetables and fruit. Adequate expenditure on fruit and vegetables was estimated to be R302 per person per month.

The Statistics South Africa poverty datum line of R620 per person per month (Statistics South Africa, 2011) was inflated to figure of R736.23 per person per month to be made comparable with the survey data collected.

An evaluation of adoption rates of urban agriculture was then done by means of a detailed interview with Soil for Life. The purposes of the interview were: to develop an understanding of their training programme, how it is implemented in communities, the way in which progress of their participants is monitored, and, most importantly, the percentage of participants who continue to garden after completing the programme. From this information, it was anticipated that a measure of adoption rates could be established, along with the reasons why programme participants were shown to discontinue gardening. Analysis then turned to assessing the levels of urban agriculture that existed within Lavender Hill. The survey was structured such that information could be obtained regarding the prevalence of urban gardeners, levels of interest in gardening amongst the sample, as well as the perceived constraints that prevented community members from growing their own produce.

Limitations to our data included the failure to differentiate between participants who lived in the informal settlements and those who lived in formal housing. This 
reduced our ability to make conclusions regarding the different space constraints faced by these two types of housing. Another limitation was that, as Mothers Unite is an organisation focused on combatting food instability, survey participants may have been more aware of the importance of good nutrition than the average person in the community, which limits our ability to extrapolate from these findings. Finally, despite our best efforts some respondents struggled to answer the questionnaire in English.

\section{RESULTS}

Potential savings to be made by food gardening

Table 1 provides information about household characteristics in the Lavender Hill sample. Disposable household income varies from R1,000-8,000 per month and per capita income from R251-2,000 per month. Mean per capita income lies well below the poverty datum line of R736 per month. On average people spend half their income on food, but in some cases households spend more than $80 \%$ of their income on food. Almost two thirds (64\%) of households in the sample reported incomes which places them below the Statistics South Africa poverty datum line. Just over half of the respondents indicated that they are actively seeking employment; we do not know how many of the rest are employed and how many are discouraged workers who have given up on ever finding work. A full $82 \%$ of respondents indicated that they believe food shortages to be an issue in their community.

Table 1: Food consumption habits of Lavender Hill households $(n=44)$

\begin{tabular}{lccc} 
Household characteristic & Mean & Min & Max \\
\hline Household size & 4.37 & 1 & 8 \\
Household disposable income (R/month) & 2,714 & 1,000 & 8,000 \\
Per capital disposable income (R/month) & 691 & 251 & 2,000 \\
Food budget (R/month) & 1,379 & 250 & 3,500 \\
$\%$ of total income spent on food & $50 \%$ & $21 \%$ & $89 \%$ \\
Money spent on vegetables (R/month) & 265 & 50 & 800 \\
PC money spent on vegetables (R/month) & 63 & 10 & 160
\end{tabular}


$\%$ of total income spent on vegetables

$\%$ of the food budget spent on vegetables
$11 \%$

$23 \%$
$2 \%$

$5 \%$

$29 \%$

$60 \%$

$\%$ of households spending less than R302/per

person/ month on vegetables

$100 \%$

$\%$ respondents who would prefer more

vegetables in their diet

$77 \%$

Nutrition levels are appalling in the community. Vegetables on average comprise $11 \%$ of the household food budget and $23 \%$ of disposable income, and never amount to the recommended level of R302 per person per month. In the extreme case expenditure on vegetables took up $29 \%$ of household income. This statistic is substantiated by the fact that $82 \%$ of the sample was concerned about the amounts of food consumed within the community, while $77 \%$ of the sample expressed dissatisfaction with the amounts of vegetables consumed in their diets.

Given this poverty and food insecurity it is unsurprising that Soil for Life is finding a substantial demand for training in the community. The organisation reckons that of the typical intake of fifteen trainees, $80 \%$ will complete the training program and $90 \%$ of those who have completed will follow through to actually plant a garden. About one in five gardens will be abandoned during the first year and about fifty per cent will be abandoned in the course of the first four years. Odendaal et al. (2013) reported similar dropout rates for SEED elsewhere on the Cape Flats. Based on this assessment one can conclude that the benefits of gardening, be it better tasting food or a more secure supply of it, or simply the networking benefits of belonging, outweighed the cost of participating in the program for half the trainees. According to Soil for Life the main reasons for programme participants to abandon gardening was losing interest or external shocks such as the death of a family member or even finding a job.

\section{Barriers to Adoption}

According to survey responses, if households were able to grow enough vegetables to no longer need store-bought vegetables, they would save an average 
of $11 \%$ of their total monthly income. While some studies suggest that complete subsistence is not possible in an urban context (Reuther and Dewar, 2007), Soil for Life Ambassadors are already doing so in Lavender Hill. For example, Suelyla Dya, pictured in her small container garden at home below, is already producing enough to feed a family of seven.

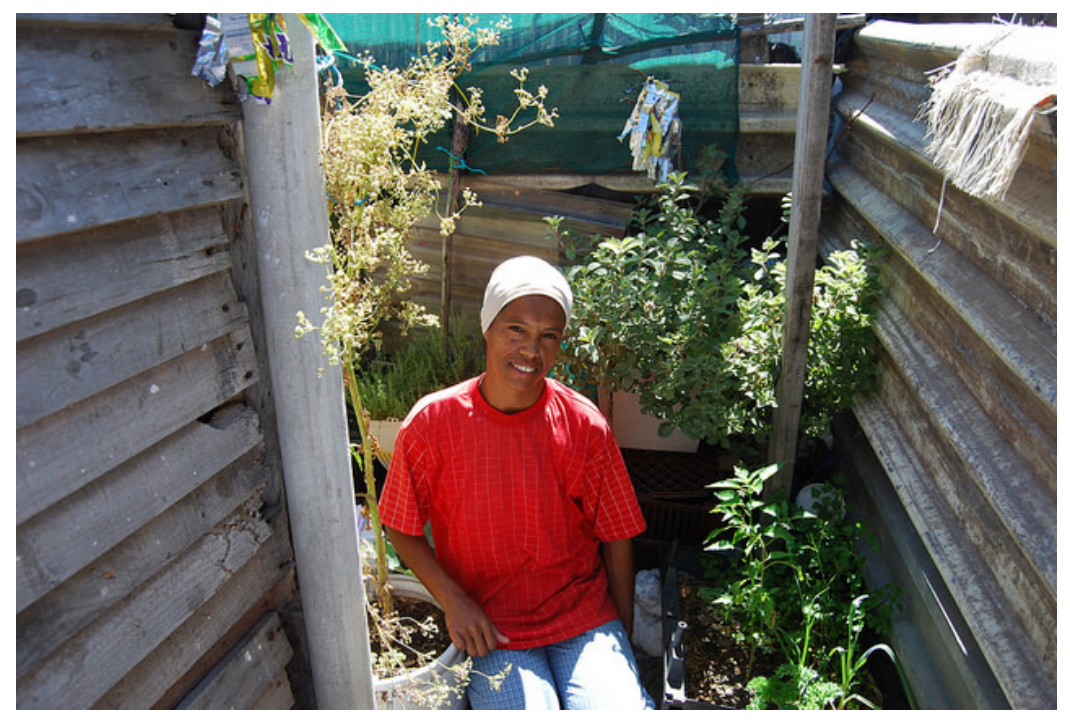

Figure 1: Suelyla Dya of Lavender Hill in her container garden at home

Complete self-reliance can act as a buffer to external supply shocks such as the food price hike that resulted from the economic recession of 2008 (Rogerson, 2003; Battersby Leonard, 2011). However, complete reliance on in-home produce has also been seen to make residents susceptible to seasonality shocks, showing that complete self-reliance may be possible during fruitful growing periods, but can leave gardeners vulnerable to shortages when seasons change. In the study of a township in the Eastern Cape conducted by Thornton (2008), it was seen that household gardeners were only able to save money usually spent on vegetables during the months from September to December. These authors argued that it is unrealistic to expect year round self-sufficiency, and pleaded for horticulturalists to be included in policy-making and project implementation. Doing so would ascertain when the most appropriate months are to garden, and to therefore adjust resource allocation such that gardening is primarily done when it is most productive and reliable. Seasonal gardening would require community members to rely on a 
multitude of livelihood strategies, thereby decreasing their vulnerability to external shocks. The current division of labour whereby the Western Cape Department of Agriculture does rural food security projects and the City of Cape Town works on urban agriculture is problematic, because it starves urban agriculture of the necessary agricultural expertise such as agronomy, irrigation and soil science.

\section{Table 2: Attitudes and constraints to participating in household food gardening $(n=44)$}

\begin{tabular}{ll}
\hline Item & Frequency \\
\hline
\end{tabular}

Are you an experienced gardener?

$\%$ who had never gardened before

$63 \%$

$\%$ who have gardened before, but stopped

$9 \%$

$\%$ who are currently gardening

$27 \%$

What would be your main objective with growing a garden?

$\%$ willing to grow and sell produce $56 \%$

$\%$ willing to grow but not willing to sell produce $29 \%$

$\%$ willing to sell but not grow $5 \%$

$\%$ not willing to grow, nor sell

$10 \%$

What is your main constraint to taking up home food gardening?

$\%$ who listed space $57 \%$

$\%$ who listed cash flow $28 \%$

$\%$ who listed time $11 \%$

$\%$ who listed other $4 \%$

It is a key question whether Suelyla Dya's success can be scaled up to the entire community. According to Table 2 almost two thirds of the Mothers Unite women have never gardened before, about a quarter are currently in the programme 
and almost one in ten have stopped growing their gardens. Despite these relatively low levels of household gardening, an interest in gardening was widely expressed, with $85 \%$ listing a willingness to grow their own vegetables. More than half of the group were open to the idea of growing vegetables for both consumption and selling purposes, while $29 \%$ were willing to do it solely for consumption. This is unusual as previous studies have shown that people are more likely to grow gardens for home use than to produce vegetables for sale (Nugent, 2000). This is usually because people in townships find it expensive and difficult to compete in formal markets (Geyer et al., 2011; Thom and Conradie, 2012). Amongst those interviewed the main perceived constraints were a lack of yard space in which to set up even container gardens $(57 \%)$ and a lack of cash flow $(28 \%)$. Time constraints were not considered a barrier for adoption by many people (11\%), which is consistent with the large proportion of people who have indicated that they are currently searching for a job. Space is a severe constraint in Lavender Hill (City of Cape Town, 2012). It is important, with regard to space, to differentiate between the formal and informal housing settlements within the Lavender Hill area. Many people living in the informal section have very limited yard or outside space in which to garden. Several survey participants listed reasons that pertained to property rights also being an issue. This is due to plots not being fenced off properly which can result in damage to gardens by uncaring neighbours as well as encouraging potential theft.

According to Soil for Life, the total economic cost of setting up a garden is approximately $\mathrm{R} 3,500$ per homestead. SEED quoted similar figures of $\mathrm{R} 2,456$ per garden and R2,231 per trainee (Odendaal et al., 2013). This amount is significant as it is approximately one-and-a-half times the average community member's monthly income. At the level of poverty prevalent in Lavender Hill, investment in gardening is an immense risk, especially when a favourable outcome is not guaranteed and the success thereof is susceptible to uncontrollable variables such as climatic conditions and pests (Reuther and Dewar, 2007). However, it must be kept in mind that beneficiaries are expected to make token contributions only. Therefore education and the lack on ongoing motivation of the homestead gardeners must be considered more important constraints than the financial cost of setting up the gardens. 
The environmental conditions on the Cape Flats make gardening a challenge. Limited summer rainfall and strong south-easterly winds increase evaporation rates which necessitates supplementary irrigation during the hotter months (Reuther and Dewar, 2007). In summer, crops are watered from municipal sources, grey water or rainwater tanks (Odendaal et al., 2013), sources which are expensive or limited. While several people mentioned the difficulty of accessing water for their gardens nobody mentioned the cost of water. Perhaps the prevalent payment of non-payment for municipal services (Smith and Hansen, 2003), makes the cost of water irrelevant. Alternatively the respondents to our survey were simply too inexperienced to anticipate that the cost of water would be a substantial ongoing expenditure. The problem of high evaporation is further exacerbated by very poor sandy soils, which returns low yields unless heavily composted (Reuther and Dewar, 2007). Homestead gardening programs usually start off by supplying free compost, but expect beneficiaries to become self-sufficient in time (Odendaal et al., 2013). It is possible in principle to be self-sufficient in terms of compost, but container gardens plus household waste typically do not produce enough compostable material to become self-sufficient in this regard. Although we do not have direct evidence of it, we suspect that the availability of compost or the lack of availability thereof might be a major reason for people abandoning their home gardens. The fact that nobody mentioned compost as a barrier to adoption, again speaks to a lack of understanding of the effort involved.

According to Soil for Life, the gardening project in Lavender Hill is in decline, which is interesting given that so many of the Mothers Unite women expressed an interest in it. Some of the exogenous factors working against participation in gardening projects include increases in the availability of government grants (Thornton, 2008) and poor socio-economic circumstances which account for a lack of motivation. What is likely to happen is that community members are attracted by the idea of gardening and by the fact that this is a free resource, but very quickly become disillusioned by, or disinterested in, the process. Given the government's commitment to the continued provision of social grants and public benefit organisations' limited resources, it is likely that Suelyla Dya's success will remain the 
exception and will not become the norm any time soon. Even in the long run, only a deep commitment to education and training is likely to make a discernible impact.

\section{CONCLUSION}

This survey found that the average person in Lavender Hill lives under the official poverty datum line and that employment prospects are limited. None of the households surveyed currently can afford to buy the recommended five a day fruit and vegetables in the formal market and the substantial proportion of household income spent on vegetables suggests that there ought to be considerable interest in urban food gardening. In some respects the survey confirmed such interest, although mostly amongst a constituency who does not really have good understanding of what would be involved. The survey also revealed that a non-trivial number of women who have been recruited into the programme no longer find it worthwhile to continue gardening. This finding is consistent with Soil for Life's observation that their homestead gardening project in the community is in decline.

In a sense this survey has raised more questions than it has answered. For example, why do women drop out of the Soil for Life programme in Lavender Hill? Economic theory suggests that the costs involved in gardening simply outweigh its benefits. The next question is what are the costs or barriers to continued gardening? Soil of Life charges almost nothing and we think the organisation continues to provide highly subsidized seedlings and compost for a period of up to four years for everyone who continues to work his or her garden. If out of pocket costs are not the issue, then perceived benefits might be. While we have a long list of the potential benefits, and some sense that this list might resonate with people who are not currently in the programme, we do not yet know which of those benefits serve as motivation for people who are in the program to continue with it. For those who dropped out, we do not know what the biggest disappointments were. For this reason we cannot begin to tailor a better programme. Until we do, all that can be said is that if public or donor money is to be spent on urban agriculture, it is important that the implementing organisation makes very sure that the community actually wants it, and does not just use the programme as a way of leveraging a good time (interesting training programme, nice food) or other government services. 
In addition, potential beneficiaries must be screened very carefully and the programme must continue to invest in the self-efficacy of these people it tries to empower.

\section{ACKNOWLEDGEMENTS}

We would to thank Soil for Life and Mothers Unite for providing access to the community and everyone who participated for their time.

\section{REFERENCES}

Austen, A., Visser, A. 2002. Study Report: Urban Agriculture in South Africa. CSIR Report BOU/1243, Pretoria.

Battersby Leonard, J. 2011. The State of Urban Food Insecurity in Cape Town. Urban Food Security Series 11: 1-42.

City of Cape Town. 2007. Urban Agriculture Policy for the City of Cape Town. Available Online: http://www.capetown.gov.za/ [3 April 2014]

City of Cape Town, 2012. Cape Flats District Plan. Available online: http://www.capetown.gov.za/ [accessed: 5 April 2014].

Geyer, H., Schloms, B., du Plessis, D., van Eeden, A. 2011. Land Quality, urban development and urban agriculture within the Cape Town Urban Edge. Town and Regional Planning 59: 41-52.

Lynch, K., Binns, T., Olofin, E. 2001. Urban agriculture under threat: The land security question in Kano, Nigeria. The International Journal of Urban Policy and Planning 18 (3): 159-171.

Nugent, R. 2000. The impact of urban agriculture on the household and local economies. Thematic paper 3 in "Growing cities, growing food" (ed) N. Bakker. Deutsche Stiftung für Internationale Entwicklung, Zentralstelle für Ernährung und Landwirtschaft, 2000 
Odendaal, R., Morar, J., Conradie, B. 2013. A cost benefit analysis of a technology bundle aimed at improving the resilience of urban households in Rocklands, Mitchells Plain. CSSR Working Paper No. 332.

Page, B. 2002. Urban agriculture in Cameroon: an anti-politics machine in the making? Geoforum 33 (1): 41 - 54.

Reuther, S., Dewar, N. 2007. Competition for the use of public open space in lowincome urban areas: the economic potential of urban gardening in Khayalitsha, Cape Town. Development Southern Africa. 23(1): 97-122.

Rogerson, C. 2003. Towards "pro-poor" urban development in South Africa: the case of urban agriculture. Urban Forum 14 (1): 53-79.

Rogerson, C. 2011. Urban Agriculture and Public Administration: Institutional Context and Local Response in Gauteng. Urban Forum 22 (2): 183-198.

Ruysenaar, S. 2013. Reconsidering the 'Letsema Principle' and the Role of Community Gardens in Food Security: Evidence from Gauteng, South Africa. Urban Forum 24 (2): 219-249.

Shisanya, S., Hendricks, S. 2011. The contribution of community gardens to food security in the Maphephetheni uplands. Development Southern Africa 28 (4): 509-526.

Slater, R. 2001. Urban agriculture, gender and empowerment: An alternative view. Development Southern Africa 18 (5): 635-650.

Smith, L., Hanson, S., 2003. Access to water for the urban poor in Cape Town: where equity meets cost recovery. Urban Studies 40(8): 1517-1548.

Statistics South Africa, 2011. Subjective poverty in South Africa: findings of the living conditions survey 2008/2009. Available online: http://www.statssa.gov.za/publications/Report-03-10-01/Report-03-10012009.pdf [Accessed: 21 April 2014].

Thom, A., Conradie, B. 2012. Promoting Urban Agriculture for Development: Suggestions for Designing the 'Ideal' Social Enterprise Box Scheme in Cape Town. CSSR Working Paper No 316.

Thornton, A. 2008. Beyond the Metropolis: Small Town Case Studies of Urban and Peri-urban Agriculture in South Africa. Urban Forum 19 (3): 243-262.

Webb, N. 1998a. Urban agriculture. Urban Forum 9 (1): 95-118. 
Webb, 1998b. Urban cultivation: Food crops and their importance. Development South Africa 15(2): 201-223.

Webb, N., Kasumba, H. 2009. Urban agriculture in Ezibeleni (Queenstown): Contributing to the empirical base in the Eastern Cape. Africanus 39 (1): 2741.

Webb, N. 2011. When is enough, enough? Advocacy, evidence and criticism in the field of urban agriculture in South Africa. Development Southern Africa 28 (2): 9-27.

Zezza, A., Tasciotti, L. 2010. Urban agriculture, poverty, and food security: Empirical evidence from a sample of developing countries. Food policy 35 (4): 265-273. 